\title{
Correlation of the Haptic Perception and Technical Parameter
}

\section{Corrélation du Perception Haptique et du Paramètre Technique}

\author{
Annika Neumann, ${ }^{1 a}$ and Robert Schmitt ${ }^{1}$ \\ ${ }^{1}$ Chair for Metrology and Quality Management, RWTH Aachen University, Steinbachstr. 19, 52074 Aachen, Germany
}

\begin{abstract}
A priori knowledge of the customer's perception of a product is a precondition to reduce efforts in product development and therefore diminish costs. This paper presents the results of a study analyzing the correlation between the haptic perception of surfaces and the technical measured parameters using the example of roughness. A methodology has been developed that allows objectifying specific haptic quality characteristics. Important impacts on the perception are the structure and the material of the surfaces. Three experimental studies have been conducted to investigate specific characteristics of haptic perception. The first study examines the different haptic perceptions regarding different geometrical surface structures, assuming that the subjects are able to differentiate geometrical surfaces with different technical parameters. The second experiment studies the perceived haptic relation between two surfaces that have the same technical roughness, but differ in surface structure. The structure types can be differentiated in natural (stochastic, e.g. leather) and in artificial (geometrical) surfaces. The third study concerns the hedonic evaluation of previously analyzed natural and geometrical surfaces to identify the preferences of the customer. The presented findings enable the application of the methodology in terms of customer orientated product development.

Résumé. A priori la connaissance de la perception du client d'un produit est une condition préalable pour réduire les efforts dans le développement de produits et donc de diminuer les coûts. Cet article présente les résultats d'une étude analysant la corrélation entre la perception haptique des surfaces et les paramètres mesurés techniques utilisant l'exemple de la rugosité. Une méthodologie a été développée qui permet d'objectiver les caractéristiques spécifiques de la qualité haptiques. Des impacts importants sur la perception sont la structure et le matériau des surfaces. Trois études expérimentales ont été réalisées pour étudier les caractéristiques spécifiques de la perception haptique. La première étude examine les différentes perceptions haptiques concernant différentes structures de surface géométriques, en supposant que les sujets sont capables de différencier les surfaces géométriques avec différents paramètres techniques. La deuxième expérience étudie la relation perçue haptique entre deux surfaces qui ont la même rugosité technique, mais qui diffèrent par la structure de surface. Les types de structure peuvent être différenciées en naturel (stochastique, par exemple, cuir) et artificiels (surfaces géométriques). La troisième étude concerne l'évaluation hédonique des surfaces naturelles et géométriques précédemment analysés pour identifier les préférences du client. Les résultats présentés permettent l'application de la méthodologie en termes de client orienté le développement de produits.
\end{abstract}

\section{INTRODUCTION}

Most consumer products share the same basic functions amongst their categories. Therefore, differentiation becomes more and more challenging. In many cases, designers focus on product function and the visual design, disregarding costumer's haptic perception [1]. Garvin [2] described the Perceived Quality (PQ) as a very ambiguous construct. E.g. the image of a company [3], the experiences of the user [4] and the sensory perception during the interaction with the product [5] influences the evaluation of it. Lederman and Klatzky [6] show 1993, that the haptic impression is the major factor of $\mathrm{PQ}$ during the exploration by the customer [7]. In 2008 Schmitt et al. [8] developed a structured approach, which

\footnotetext{
a Corresponding author: a.neumann@wzl.rwth-aachen.de
}

enables the manufactures to break down the holistic impression of a product into technical parameters.

This work presents the results of a set of studies in which geometrical and stochastic surfaces have been analysed in terms of their perceived roughness. First, the differentiation of different samples has been evaluated. Next, it has been analysed, if the structure has an influence on the perception of roughness. Finally, the human preference has been investigated for in total 96 different surfaces.

\section{STATE OF RESEARCH}

Multiple studies were conducted that focused on the relation between technical measurement and subjective 
perception of surfaces regarding their roughness. However, very few targeted specific methods that support the assessment of roughness perception. The connection between technical parameters and human perception forms the basis and motivation for this paper.

Bergman and Tiest have conducted several tests on perceived roughness. One of which included 12 subjects that had to rate a total of 96 surfaces. The correlation coefficient between evaluation and physical measurements (e.g. $R_{a}, R_{z}$ ) ended up between 0.4 and 0.8 varying amongst the subjects. They concluded that the physical roughness deviates from perceived roughness. [9]

Chen et al. focused on the connection of perception and physical characteristics of packaging materials. One study featured 37 packaging material surfaces that had to be rated on six semantic scales, like warm/cold and smooth/rough. The subjects were asked to give a statement on their hedonic impression (like, do not like, unsure). The outcome of the study was a correlation coefficient of $\mathrm{R}^{2} \sim 0.6$ between the physical characteristics $\left(\mathrm{R}_{\mathrm{a}}\right)$ and roughness perception. [10]

Hollins and Bensmaia reviewed the correlation between measureable surface characteristics and roughness perception. Their conclusion included that the spatial period $(>0.2 \mathrm{~mm})$ of relatively rough surfaces is a good parameter for perceived roughness. In order to characterize finer surfaces (spatial period $<0,2 \mathrm{~mm}$ ), they performed a comparative study where two different surfaces were moved against the index finger of subjects and the subjects had to point out which surfaces was rougher. The result was that vibrations on the skin are connected to the roughness level of the surface. This outcome supports the hypothesis that the movement of the skin on a surface activates the Pacinian corpuscles, which is responsible for the characterization of finer surfaces. [11, 12]

Lederman and Taylor conducted some studies on perceived roughness. 8 surfaces with different groove widths were analyzed by subjects regarding the perception of roughness. The result of the studies is the influence of the groove width on the perceived roughness. [13]

Yoshioka et al. performed psychophysical and neurophysiological studies with different predefined surfaces. The result of their studies was, that the same neural mechanism accounts the perceived roughness weather is a fine or a coarse surface. [14]

In summary of all of those studies there is no method that sufficiently relates human perception of roughness to physical parameters of the materials. In order to achieve a proper method, descriptors had to be found that are the most meaningful for the characterization. After that, appropriate measurements for these descriptors had to be identified.

\section{Sensory studies}

One method to objectify parameters from human perception is the so-called profile method (DIN 10967-1 [15]), which is mainly used in the food industry to describe food by its aromas. The descriptors represent different aromas. Falk et al. [16] designed a method to analyze haptic perception, which is based on the profile method, in two research projects (16134 BG, DFG SCHM 1846-34/1). In contrast to the food aromas the descriptors for haptic perception are not yet unified and thus the method consists of step A (identification) and step B (characterization). Step A includes expert workshops where trained subjects (experts) specify their perception by different descriptors. After that the descriptors were ranked by the means of a pairwise comparison and the most important descriptors were identified. Step B will target the preferences of human test persons by discriminatory testing. First, test samples have to be identified and analyzed. After that a preliminary study has to be conducted in order to verify that differences between the samples can be identified. Lastly, the preliminary study has to be validated by naïve subjects (untrained test persons). [17]

\section{Measurement of surface roughness}

In order to meet roughness specifications several measuring methods have been developed to gather data of initial surface roughness for machined parts such as bearings or shafts. ISO 4287 [18] specifies distinctive values for roughness (R-values) that are applicable when measuring a profile (2D). Some of which are the medium groove width $R_{S m}$, the medium arithmetic roughness $\mathrm{R}_{\mathrm{a}}$, and the maximum profile roughness profile height $\mathrm{R}_{\mathrm{z}}$. ISO 25178 [19] targets surface measurements and defines distinctive values for surfaces (S-values).

Recording of surface profiles is done using profilometers, which can be divided into optical and tactile profilometers. Optical means the use of infraredlasers that result in a finer resolution than the tactile method. Diamond needles and a displacement transducer are used in tactile profilometers. For 3D analysis structured light 3D-scanners are used which are able to measure up to $8 \mathrm{~mm} \times 6 \mathrm{~mm}$ at once. Those profilometers have a range of resolution between $4-0.1 \mu \mathrm{m}$. [20]

According to DIN 1319 [21] a measure is a predefined value. However, Bortz and Döring specify measurement as assigning values to an object, which not necessarily have to be physically predefined [22]. Based on this definition sensory studies are a form of measurement where descriptors are quantified. Moreover, every technical method that gathers data to draw conclusions on descriptors is a measurement procedure.

\section{METHODOLOGY}

\subsection{Selection of materials}

Different studies in cooperation with different companies show that the quantification of haptic perception is of high interest for the automotive industry. This is the reason why leather-like surfaces have been selected. Spingler [23] mentioned 2011, that the haptic perception of roughness might depend on the surface structure. Therefore the presented approach is assessing different surface structures. 
Geometrical surfaces: To check which parameter has a direct influence on the tactile perception of roughness, it was necessary to produce surface samples with predefined parameters for our analysis. The findings of Lederman and Taylor [13] and Yoshioka et al. [14] show that the haptic perception of roughness depends mainly on the groove width and ridge width, therefore these were individually varies. For the structure of the geometric surfaces, lines and diamond shapes were chosen (see Table1) because their shapes are typical for leather surfaces. Nitrile rubber was selected as material because of its good abrasive properties, which are important for the tactile examination. Furthermore, the material is comparable with leather used in car manufacturing. The geometric surfaces have been prepared with a laser. To ensure that the results of the haptic study are not affected, all surfaces were manufactured in the same size $(70 \mathrm{~mm} x$ $50 \mathrm{~mm})$. The 48 surfaces with the artificial geometrical surfaces, were varying in the groove (set " $A$ " \& " $C$ ") and in the ridge width (set "B" \& " $D$ "). The samples with the numbers from 00 to 11 are ascending in groove and ridge width. The samples with 00 have the smoothest surfaces and the samples with 11 have the roughest surface according to measurements. Two sets were designed to have a diamond-shaped structure (set "A" \& set "D") and two sets of surfaces were designed to have a linear structure (set "B" \& set "C").

Table 1 Overview of the geometrical surface structures

\begin{tabular}{|c|c|c|c|c|}
\hline Set-name & Set-A & Set-B & Set-C & Set-D \\
\hline Abbr. surface & RaRL & LiRP & LiRL & RaRP \\
\hline Structure & $\begin{array}{l}\text { diamond } \\
\text {-shaped }\end{array}$ & linear & linear & $\begin{array}{l}\text { diamond } \\
\text {-shaped }\end{array}$ \\
\hline variable parameter & $\begin{array}{l}\text { groove } \\
\text { width }\end{array}$ & $\begin{array}{l}\text { ridge } \\
\text { width }\end{array}$ & $\begin{array}{l}\text { groove } \\
\text { width }\end{array}$ & $\begin{array}{l}\text { ridge } \\
\text { width }\end{array}$ \\
\hline constant parameter & $\begin{array}{l}\text { ridge } \\
\text { width }\end{array}$ & $\begin{array}{l}\text { groove } \\
\text { width }\end{array}$ & $\begin{array}{l}\text { ridge } \\
\text { width }\end{array}$ & $\begin{array}{l}\text { groove } \\
\text { width }\end{array}$ \\
\hline $\begin{array}{l}\text { Example of the } \\
\text { structure }\end{array}$ & 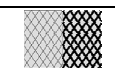 & 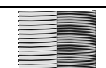 & & \\
\hline
\end{tabular}

Stochastic surfaces: According to Yoshioka the spatial period $(R S m)$ value is one of the most important factors for the perception of roughness. Surfaces with smoother and rougher surface structures regarding the $R S m$ value vary in their haptic perception. Due to that fact two sets with 12 surfaces (in total 24) with common materials have been selected as natural surfaces. Additionally further technical parameters $\left(S_{s k}, S_{a}, S_{v}, S_{k u}\right)$, were evaluated which showed the best correlation with the haptic perception of the geometrical surfaces (see table 4). Materials like different sandpapers (A3, A5, A6, A7, SP1, SP3), wallpapers (P1, P4, P6, P7), corrugated cardboard (P8), wood (H3), cellular rubber (K1), leather (L2, L7, L9, L10), leather grain (B6, B7) and leather imitation (KL6, KL11, KL12) have been selected. To ensure that the results of the haptic study are not affected, all surfaces $(70 \mathrm{~mm} \times 50 \mathrm{~mm})$ were cut in the same size. Additional a variety of 24 surfaces, mainly leather and leather imitations have been selected for the third study, to assess the preferences of the subjects. An overview of the stochastic surfaces with its correlation coefficient of the haptic perception and the technical parameters is given in table 2 .
Table 2 Overview of the stochastic surface structures

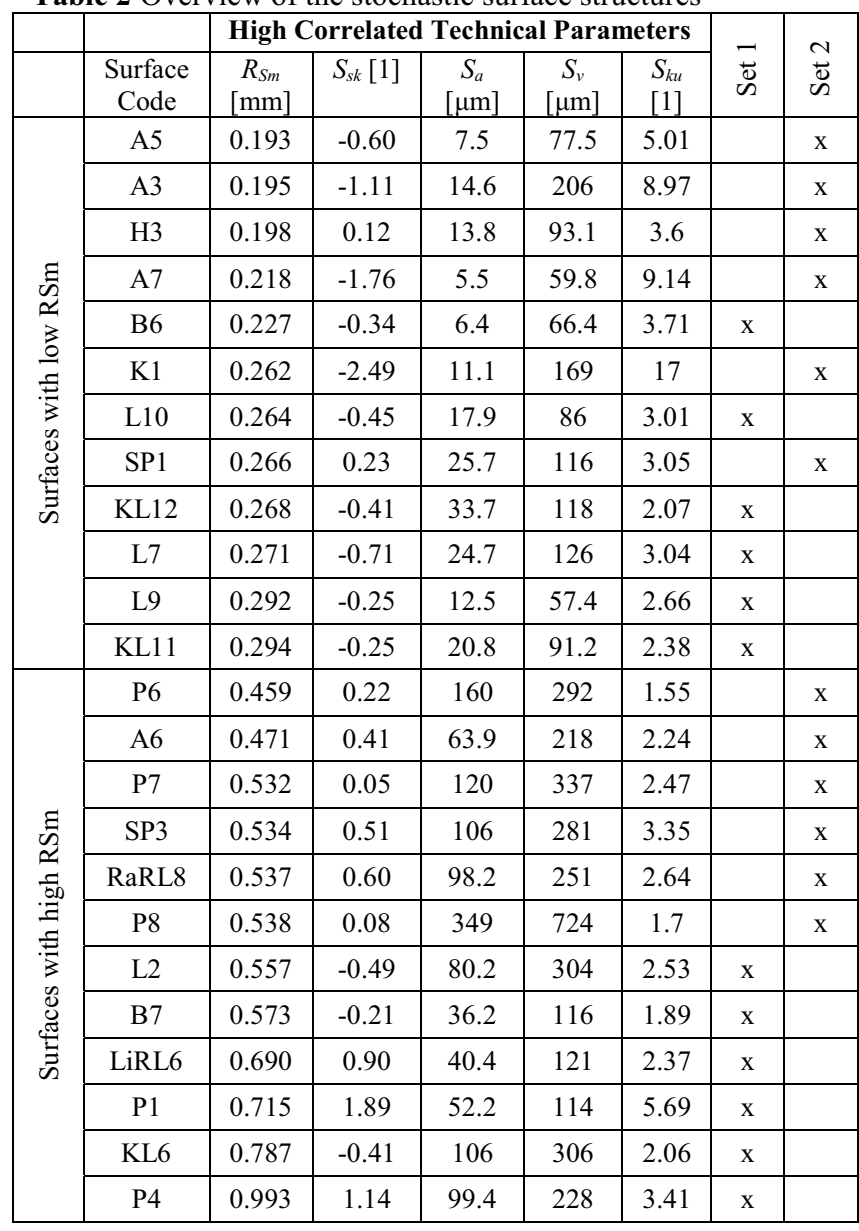

Measurement of the surface roughness: The 48 geometrical surfaces and the 48 stochastic surfaces were measured by using a 3D-profilometer (Alicona Infinite Focus) to generate 3D-profiles of every surface. For the data evaluation 13 2D-roughness-paramters $(R)$ (ISO 4287 [18]) and 10 3D-roughness-parameters ( $S$ ) (ISO 25178 [19]) were selected out of 167 different characteristics for each surface.

\subsection{Applied methodology}

To evaluate the haptic perception of roughness regarding different surface structures and their hedonic preferences an approach of three steps is necessary. Step1 is a sensory study using a ranking test to evaluate, if the subjects are able to differentiate the geometrical surfaces. Step 2 is a sensory study using pairwise comparison to evaluate, if the same technical measured roughness but different surface structure is perceived different or identical. Step 3 is the last sensory study (hedonic test) to assess the preferences of the subjects for all previous analysed surfaces for two different use cases.

Step 1: To check whether the subjects are able to distinguish different surfaces with the same structure and different technical forms a ranking test was conducted. Four different sets, each consisting of 12 surfaces, have been analysed. In order to ensure the subjects ability to judge the rank orders, three surfaces were used per test in a sequence. The distance of the samples, in relation to the 
technical values per surface, was systematically reduced. The samples were handed to the subjects in a random order to avoid influences of the results created by a routine of the subjects. The ranking test was started, for example with the surfaces $00 ; 05 ; 10$ a gap of 5 and was finished with the surfaces $07 ; 08 ; 09$ with a gap of 1 . In total 30 rank tests were performed (see also Table 3 for the test set-up). Following the ranking test every set of twelve surfaces was brought into order by the subjects. The samples were sorted on a scale from 0 to 100,0 being the lowest and 100 the highest perceived roughness. The data from the studies and the 3D-profile measurements were analysed using SPSS, Minitab and Excel software solutions. Correlations show which technical parameter represents the haptic perception best. Based on those results the selection of the material for the pairwise comparison (in the following step) took place. In the first study 102 subjects participated. The instructions of the developed questionnaire were followed by each subject.

Step 2: To verify if the subjects are able to distinguish surfaces with the same technical roughness and different surface structures, a pairwise comparisons was performed in the second study. Two different sets, each consisting of 12 surfaces with natural (stochastic) and artificial (geometrical) surface composition have been analysed. 6 of the 12 surfaces had smaller $R_{S_{m}}$ values and 6 of the 12 surfaces had higher $R_{S m}$-values. The approach of Wickelmaier [24] has been adapted for haptic perception. In total 66 pairwise comparisons per set were conducted. In sum, each subject has carried out 132 Pairwise comparisons. In the second study 62 subjects participated

Step 3: The preference tests were carried out using a JAR scale (Just-About-Right-Scale). Prior to the study an example of application was defined for the preference test. During the preference test the subjects evaluated the individual surfaces from studies 1 and 2, as well as other leather and synthetic leather surfaces. In total 96 different surfaces have been assessed by two groups. First group of 102 subjects assessed 48 geometrical surfaces. Second group of 62 subjects assessed 48 stochastic and geometrical surfaces.

\section{RESULTS AND DISCUSSION}

The results of the three steps are stated below.

Step 1: The results of the human perceived roughness evaluation were analysed with the Friedman test [25]. It represents a two-factor analysis of variance for ranking numbers [26]. According to DIN ISO 8587 [27], it allows the detection of differences between the samples of the perception of the subjects. The null hypothesis states that there is no perceived difference between the samples. The alternative hypothesis $\mathrm{H}_{1}$ expresses, that the haptic perception is not equal. The Friedman test value is calculated according to the following formula:
$F_{\text {test }}=12 /\left(j^{*} p^{*}(p+1)\right) *\left(R_{l}{ }^{2}+\ldots+R p^{2}\right)-3 j(p+1)$

$j=$ number of valid subjects

$p=$ number of different samples

$R_{i}=$ rank sum of the samples $i$

The results of the Friedman test show, that the subjects have mostly chosen the same ranking for the three samples during the rank test. This is the reason to reject the null hypothesis (see table 3). All rank tests of the study were analysed with the Friedman test, calculating a significance value. The following table 3 shows the results of the determined significant values. If those are under the significance level of 0.001 , the value of 0.000 is issued by the software.

Table 3 Significance value of the ranking test using the Friedman test

\begin{tabular}{|c|c|c|c|c|c|c|c|}
\hline \multirow[t]{2}{*}{$\begin{array}{c}\text { Gap } \\
\text { between } 2 \\
\text { samples }\end{array}$} & \multirow[t]{2}{*}{$\begin{array}{c}\text { Number } \\
\text { of rank } \\
\text { test }\end{array}$} & \multicolumn{2}{|l|}{$\begin{array}{c}\text { Test set-up } \\
\text { (surface numbers) }\end{array}$} & \multicolumn{4}{|c|}{$\begin{array}{c}\text { Significance level of } \\
\text { Frie dmann Test for } \\
\text { diffe rent surface } \\
\text { stretures }\end{array}$} \\
\hline & & \begin{tabular}{|l|l|l|l|l|l|l|l|l|l|}
00 & 01 & 02 & 03 & 04 & 05 & 06 & 07 & 08 \\
\end{tabular} & \begin{tabular}{l|l|l|}
09 & 10 & 11 \\
\end{tabular} & Set A & Set B & Set C & Set D \\
\hline \multirow{2}{*}{$\begin{array}{l}\text { Block I } \\
\text { gap }=4\end{array}$} & 1 & & & 0 & 0 & 0 & 0 \\
\hline & 2 & & & 0 & 0 & 0 & 0 \\
\hline \multirow{4}{*}{$\begin{array}{l}\text { Block II } \\
\text { gap = } 3\end{array}$} & 3 & & & 0 & 0 & 0 & 0 \\
\hline & 4 & & & 0 & 0 & 0 & 0 \\
\hline & 5 & & & 0 & 0 & 0 & 0 \\
\hline & 6 & & & 0 & 0 & 0 & 0 \\
\hline \multirow{6}{*}{$\begin{array}{c}\text { Block III } \\
\text { gap }=2\end{array}$} & 7 & & & 0 & 0 & 0 & 0 \\
\hline & 8 & & & 0 & 0 & 0 & 0 \\
\hline & 9 & & & 0 & 0 & 0 & 0 \\
\hline & 10 & & & 0 & 0 & 0 & 0 \\
\hline & 11 & & & 0 & 0 & 0 & 0 \\
\hline & 12 & & & 0 & 0 & 0 & 0 \\
\hline \multirow{8}{*}{$\begin{array}{c}\text { Block IV } \\
\text { gap }=1\end{array}$} & 13 & & & 0 & 0 & 0 & 0 \\
\hline & 14 & & & 0 & 0 & 0 & 0 \\
\hline & 15 & & & 0 & 0 & 0 & 0 \\
\hline & 16 & & & 0 & 0 & 0 & 0 \\
\hline & 17 & & & 0 & 0 & 0 & 0 \\
\hline & 18 & & & 0 & 0.286 & 0 & 0 \\
\hline & 19 & & & 0 & 0 & 0 & 0 \\
\hline & 20 & & & 0 & 0 & 0 & 0 \\
\hline \multirow{10}{*}{$\begin{array}{l}\text { Block V } \\
\text { gap }=0\end{array}$} & 21 & & & 0 & 0 & 0 & 0 \\
\hline & 22 & & & 0 & 0 & 0 & 0 \\
\hline & 23 & & & 0 & 0.145 & 0 & 0.106 \\
\hline & 24 & & & 0 & 0.192 & 0 & 0 \\
\hline & 25 & & & 0 & 0 & 0 & 0 \\
\hline & 26 & & & 0 & 0 & 0.068 & 0 \\
\hline & 27 & & & 0 & 0 & 0 & 0 \\
\hline & 28 & & & 0 & 0 & 0 & 0 \\
\hline & 29 & & & 0 & 0 & 0 & 0 \\
\hline & 30 & & & 0 & 0 & 0 & 0 \\
\hline \multicolumn{4}{|r|}{$j=$} & 104 & 103 & 105 & \begin{tabular}{|l|}
105 \\
\end{tabular} \\
\hline \multicolumn{4}{|r|}{$p=$} & 3 & 3 & 3 & 3 \\
\hline \multicolumn{4}{|r|}{$R_{i}=$} & 6 & 6 & 6 & 6 \\
\hline
\end{tabular}

Furthermore table 3 shows, that all samples from set "A" where differentiable by the subjects. Most samples of set "C" and set "D" were differentiable as well, with the exaptation of one rank tests in Block $\mathrm{V}$ for each set. The roughest samples from set "C" seemed more difficult to distinguish. Set "B" was the most difficult sample set to differentiate. For the subjects the smoother samples were tougher to distinguish. This result can be confirmed by the results of a 2 sample t-test of the second part of the study, in which 12 samples were classified per sample-set on a scale of $0-100$. (Results have not been published yet.)

Using the results of the rank test on a scale of $0-100$ a correlation of selected 2D-roughness-paramters $(R)$ and 
3D-roughness-parameters $(S)$ was conducted. Most of the values show a significant correlation between the technical parameter and the human perception, but non of the technical parameters is as an individual parameter capable to describe the haptic perception (see table 4).

Table 4 Correlation of technical parameter and human Perception

\begin{tabular}{|c|c|c|c|c|}
\hline & & lation wi & nan per & \\
\hline $\begin{array}{l}\text { Technical } \\
\text { Parameter }\end{array}$ & Set A & Set B & Set C & Set D \\
\hline $\mathbf{R a}[\mu \mathbf{m}]$ & 0.03 & $0.91 * *$ & $0.93 * *$ & $0.95^{* *}$ \\
\hline $\mathrm{Sa}[\mu \mathrm{m}]$ & $0.58^{*}$ & $0.72 * *$ & $0.79 * *$ & $0.78^{* *}$ \\
\hline Rku [1] & 0.1 & $0.77 * *$ & $0.64 *$ & 0.58 \\
\hline Sku [1] & 0.39 & $0.85^{* *}$ & $0.93 * *$ & $0.69 *$ \\
\hline $\mathrm{Rq}[\boldsymbol{\mu m}]$ & 0.14 & $0.91 * *$ & $0.94 * *$ & 0.89 ** \\
\hline $\mathrm{Sq}[\mu \mathrm{m}]$ & $0.6^{*}$ & 0.54 & $0.59 *$ & $0.88^{* *}$ \\
\hline Rsk [1] & 0.49 & 0.18 & 0.2 & 0.72 ** \\
\hline Ssk [1] & $0.73 * *$ & $0.91 * *$ & $0.92 * *$ & $0.88^{* *}$ \\
\hline $\mathrm{Rz}[\mu \mathrm{m}]$ & 0.2 & $0.9^{* *}$ & $0.93 * *$ & $0.93 * *$ \\
\hline $\mathrm{Sz}[\mu \mathrm{m}]$ & $0.69^{*}$ & 0.07 & 0.38 & 0.04 \\
\hline RSm [mm] & 0.4 & $0.81 * *$ & $0.64 *$ & $0.63 *$ \\
\hline
\end{tabular}

Step 2: The difference of perceived roughness between each surface within both surface sets has been tested with a seven-tiered-scale, where ' 1 ' denotes a small and ' 7 ' a strong haptic difference. All surfaces were compared with every other surface by pairwise comparison, resulting in 66 pairwise comparisons per set $(12 * 11 / 2=66)$. In order to subsequently evaluate the data with multidimensional scaling (MDS), a similarity matrix has to be established. In a first step, all surfaces were ordered by the $R_{S m}$ values with increasing values from left to right and top down. In a second step, the median of every pairwise comparison from all of the 62 subjects was calculated providing the following matrix for the two surface sets.

Table 5 Similarity matrix of set-1 (stochastic/geometric)

\begin{tabular}{|c|c|c|c|c|c|c|c|c|c|c|c|c|}
\hline Set 1 & B6 & L10 & KL12 & L7 & L9 & KL11 & L2 & B7 & LRL6 & P1 & KL6 & P4 \\
\hline B6 & 0 & 2 & 1 & 2 & 1 & 1 & 2 & 3 & 5 & 5 & 3 & 7 \\
\hline L10 & & 0 & 1 & 1 & 1 & 2 & 2 & 2 & 4 & 4 & 3 & 7 \\
\hline KL12 & & & 0 & 2 & 1 & 1 & 2 & 2 & 4 & 4 & 3 & 6 \\
\hline L7 & & & & 0 & 2 & 2 & 2 & 2 & 3 & 4 & 3 & 6 \\
\hline L9 & & & & & 0 & 1 & 2 & 2 & 4 & 5 & 3 & 7 \\
\hline KL11 & & & & & & 0 & 2 & 2 & 4 & 4 & 3 & 6 \\
\hline L2 & & & & & & & 0 & 2 & 4 & 4 & 2 & 6 \\
\hline B7 & & & & & & & & 0 & 3 & 3 & 2 & 6 \\
\hline LiRL6 & & & & & & & & 0 & 3 & 2 & 5 \\
\hline P1 & & & & & & & & & & 0 & 2 & 4 \\
\hline KL6 & & & & & & & & & & & 0 & 5 \\
\hline P4 & & & & & & & & & & & & 0 \\
\hline
\end{tabular}

It is obvious that most subjects have perceived only a small difference for surfaces with a small $R_{S m}$ value $(<0.2 \mathrm{~mm})$. Moreover, a tendency is recognizable for increasing median values from left to right within the matrix (see Table 5) suggesting that the $R_{S m}$ value affects the evaluation of roughness of the subjects. During this test stochastic and geometric surfaces have been tested in the same time. The test results lead to the assumption that the roughness of surfaces with similar technical measurements is perceived similar rough, regardless of the surface structure.

However, additional influencing factors cannot be excluded. With the help of MDS, a more intensive statistical analysis to either confirm or discard this theory may be achieved during the further analysis.

Step 3: The preference for certain surface characteristics were identified during the test using a JAR scale. The use case of an automotive arm-rest was implied. With the help of a frequency distribution it is visible, that mostly the smoother surfaces are preferred. Figure 1 shows e.g. for geometrical surfaces, that a surface with a higher technical roughness trends to be judged rougher on a JAR scale, than a surface with a smoother surface.

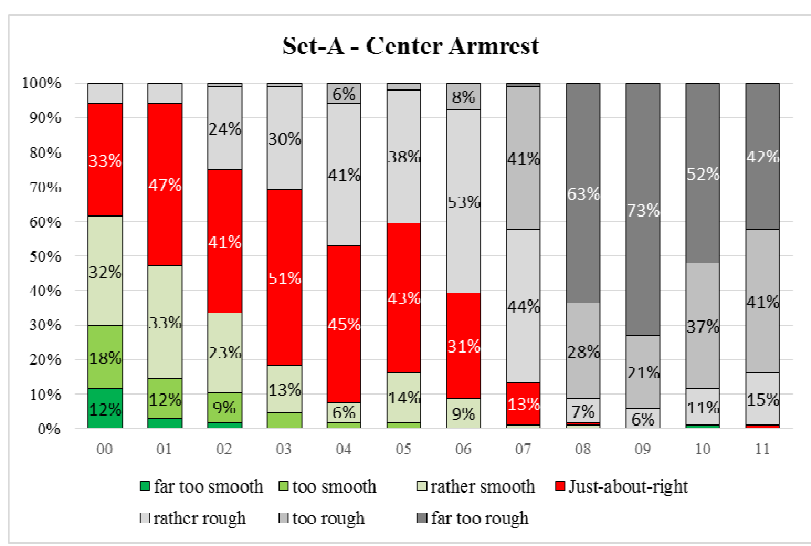

Figure 1 Frequency distribution of the descriptor roughness for a center-armrest for sample set-A (geometric)

This can be confirmed by the frequency distribution of the stochastic and geometric surfaces (see Figure 2) which are sorted by the $R_{S m}$ value. The surface B6 has the lowest $R_{S m}$ value and the surface P4 has the highest $R_{S m}$ value of this set. The surfaces with a lower $R_{S m}$ value are rated mostly in the smoother range, and the samples with a higher $R_{S m}$ value are mostly rated in the rougher range.

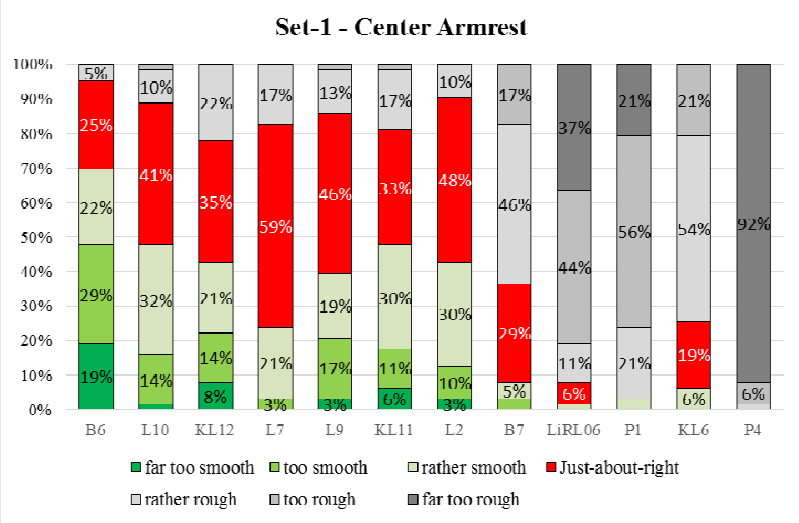

Figure 2 Frequency distribution of the descriptor roughness for a center-armrest for sample set-1 (stochastic / geometric) 


\section{OUTLOOK AND CONCLUSION}

An approach of three steps with different studies was necessary to evaluate the haptic perception of roughness regarding different surface structures and their hedonic preferences. In total 165 subjects participated in the different studies analysing 96 different natural and artificial surfaces. The surfaces were selected based on earlier findings and technical parameters. Results showed, that the surface structure does not have an influence on the haptic perception of roughness. Further investigation and analyses are necessary to prove this first assumption. The current results shows that beside the structure the different materials might have an influence on the perception of roughness, which is not describable with 2D-roughness-paramters (R) and 3D-roughnessparameters $(\mathrm{S})$. Further investigations are necessary to identify a correlation between the haptic perception and technical parameter.

\section{REFERENCES}

1. R.L. Klatzky, S.J. Lederman, The haptic glance: $A$ route to rapid object identification and manipulation. In: Gopher, D., Koriat, A. (eds.), Attention and performance XVII. Cognitive regulation of performance ; interaction of theory and application. A Bradford book, vol. 17, 165196. MIT Press, Cambridge, Mass (1999)

2. D.A. Garvin, Sloan Management Review 26, 1, 2543 (1984)

3. J. Jacoby, J.C. Olson, R.A. Haddock, Journal of Applied Psychology 55, 6, 570-579 (1971)

4. B. Frank, B. Herbas Torrico, T. Enkawa, S.J. Schvaneveldt, Journal of Retailing 90, 4, 567-586 (2014)

5. B. Grohmann, E.R. Spangenberg, D.E. Sprott, Journal of Retailing 83, 2, 237-245 (2007)

6. S.J. Lederman, R.L. Klatzky, Acta Psychologica 84, 1, 29-40 (1993)

7. A. Krishna, M. Morrin, J CONSUM RES 34, 6, 807-818 (2008)

8. R. Schmitt, B. Quattelbaum, M. Betzold, A. Enslin, B. Falk, S. Knecht, R. Lützeler, R. Mircea, T. Prefi, Wettbewerbsfaktor Produktionstechnik, 299-328 (2008)

9. W.M. Bergmann Tiest, A.M. Kappers, Acta Psychologica 124, 2, 177-189 (2007)

10. X. Chen, F. Shao, C. Barnes, T. Childs, B. Henson, International Journal of Design 3, 2, 67-76 (2009)

11. S. Bensmaïa, M. Hollins, Perception \& Psychophysics 67, 5, 842-854 (2005)

12. M. Hollins, S.J. Bensmaïa, Canadian Journal of Experimental Psychology/Revue canadienne de psychologie expérimentale 61, 3, 184-195 (2007)

13. S.J. Lederman, M.M. Taylor, Perception \& Psychophysics 12, 5, 401-408 (1972)

14. T. Yoshioka, B. Gibb, A.K. Dorsch, S.S. Hsiao, K. Johnson, Journal of neuroscience 21, 17, 69056916 (2001)

15. Deutsches Institut für Normung, Sensorische Prüfverfahren - Profilprüfung - Teil 1:
Konventionelles Profil (Beuth Verlag GmbH 10967-1 1999)

16. B. Falk, A. Neumann, F. Simon, A. Stoll, R. Schmitt, tm - Technisches Messen 81, 1 (2014)

17. R. Schmitt, A. Neumann, ATZ 115, 07-08, 616-622 (2013)

18. International Organization for Standardization, Geometrical Product Specifications (GPS), Genève 4287

19. International Organization for Standardization, Geometrical Product Specifications (GPS), Genève 25178

20. T. Pfeifer, R. Schmitt, Fertigungsmesstechnik (Oldenbourg, München 2010)

21. Deutsches Institut für Normung, Grundlagen der Meßtechnik (Beuth, Berlin

22. J. Bortz, N. Döring, Forschungsmethoden und Evaluation für Human- und Sozialwissenschaftler (Springer, Berlin 2002)

23. M.R. Spingler, Metrological System for Perceived Quality Parameters to Establish Transfer Functions to Human Perception (Apprimus, Aachen 2011)

24. F. Wickelmaier, An introduction to MDS (Aalborg Universitetsforlag, Aalborg 2003)

25. A. Quadt, S. Schönberger, M. Schwarz, Statistische Auswertungen in der Sensorik (Behr, Hamburg 2009)

26. J. Janssen, W. Laatz, Statistische Datenanalyse mit SPSS (Springer, Berlin 2013)

27. Deutsches Institut für Normung, Sensorische Analyse - Prüfverfahren - Rangordnungsprüfung (Beuth Verlag GmbH 8587 00.2010) 